\title{
ON THE FORMATION OF DOUBLE SALTS.
}

[THIRD PAPER.]

\section{THE QUESTION OF DOUBLE SALT FORMATION BETWEEN THE ALKALI SULFATES. \\ By H. W. Foote. \\ Received January 26, 19II.}

\section{Sodium and Potassium Sulfates.}

Sodium and potassium sulfates when crystallized together from solution yield homogeneous crystals containing both sodium and potassium. The question as to what these crystals are-whether a double salt or an isomorphous mixture of single salts-has been the subject of a surprising number of investigations which have yielded very contradictory results.

The older literature on this subject is well summarized by Retgers, ${ }^{1}$ who mentions at least twelve investigations. In the older work, various formulas were proposed for the crystals varying from ${ }_{5} \mathrm{~K}_{2} \mathrm{SO}_{4} \cdot \mathrm{Na}_{2} \mathrm{SO}_{4}$ to ${ }_{4} \mathrm{~K}_{2} \mathrm{SO}_{4} \cdot 3 \mathrm{Na}_{2} \mathrm{SO}_{4}$. Retgers, starting on the assumption that mixed crystals were formed and not a double salt, demonstrated first that there was not a complete series of mixed crystals, but that pure potassium sulfate may form, mixed mechanically with crystals containing a considerable proportion of sodium sulfate. He determined the specific gravity of crystals containing both sodium and potassium and found it higher than either of the single salts instead of being intermediate and concluded from this fact that a compound must be present and not mixed crystals. By fractioning his material with a heavy solution and choosing the heaviest crystals for analysis, he reached the conclusion that the substance had the composition ${ }_{3} \mathrm{~K}_{2} \mathrm{SO}_{4} \cdot \mathrm{Na}_{2} \mathrm{SO}_{4}$. Some time afterward, Bandrowski ${ }^{2}$ assigned the formula $2 \mathrm{~K}_{2} \mathrm{SO}_{4} \cdot \mathrm{Na}_{2} \mathrm{SO}_{4}$ to the crystals and Kubierschky ${ }^{3}$ obtained crystals from a hot solution corresponding in composition also to the $2:$ I salt. van't $H$ off and Barschall, ${ }^{4}$ by crystallization experiments at different temperatures, obtained crystals varying widely in composition and assumed that no compound was present, but that there was merely a limited series of mixed crystals varying in composition between 78 and $6 \mathrm{I}$ per cent. of potassium sulfate. The following year, Gossner, ${ }^{5}$ working in Groth's laboratory and aware of the work of van't Hoff and Barschall, investigated several samples of the sulfates prepared from solutions which varied greatly in composition and concluded that only the $3:$ I compound formed and that mixed crystals

\footnotetext{
12 . physik. Chem., 6, 205 (1890).

${ }^{2}$ Ibid., I7, 234 (1895).

3 Sitzb. kgl. preuss. Akad. Wiss., 1902, 413.

4 Ibid., I903, 359.

${ }^{5}$ Z. Kryst. Min., 39, 155 (1904).
} 
were not present. Finally, van't Hoff and Barschall' ${ }^{1}$ again asserted the formation of mixed crystals in opposition to the work of Gossner. It will be seen from the above review that while the majority of investigators concluded that double salts formed, nevertheless, there is good ground for assuming mixed crystals, due particularly to the work of van't Hoff and Barschall.

It has seemed to us that the problem could be settled by a method which has been used before in a considerable number of cases for determining double salts. The method consists in treating a series of mixtures of the salts with water and after thorough shaking, determining the composition of the solution and residue. Two or more mixtures having constant solubility and varying residue indicate a mechanical mixture of two substances. Varying solubility and constant composition indicate a pure double salt while varying solubility and varying composition in a series show that mixed crystals are present instead of a double salt.

The method outlined involves a considerable number of analyses and for the present purpose it was necessary that they should have a considerable degree of accuracy. Most of the previous investigators have analyzed their products merely by determining sulfate with barium chloride. This indirect method involves considerable error. The method using hydrochloroplatinic acid is much more accurate and has been used in a very few cases but as ordinarily carried out it involves converting the alkali sulfates to chlorides, which requires much time. The LindoGladding modification of the method is much more rapid and very accurate as we have convinced ourselves by experiment. By this method, the sulfates are evaporated directly with the platinum solution, treated with 80 per cent. alcohol, filtered on a Gooch crucible and washed. This leaves much sodium sulfate insoluble in the alcohol. The residue is then washed with a 20 per cent. solution of ammonium chloride, saturated with potassium platinic chloride, to remove sodium sulfate, and again with 80 per cent. alcohol, after which the potassium salt is dried and weighed as usual. We have used this method throughout the work.

In the first series of experiments, varying mixtures of anhydrous sodium sulfate and potassium sulfate were treated with water in small bottles. They were heated in a bath of boiling water for some time, then cooled and shaken in a thermostat at $25^{\circ}$ for from forty-eight hours to a week. For analysis, the solution was removed through a filter of glass wool and the residue was dried between filter paper. The salts were always very granular and they could be dried in this way very rapidly with the certainty that the impurity introduced from the solution was very small. We preferred this method to washing with water and alcohol, which has

${ }^{1} Z$. physik. Chem., 56, 212 (1906). 
sometimes been used, as the water might dissolve the single salts unequally from the crystals. van't Hoff mentions that when the latter are moistened with water, a deposit of pure potassium sulfate forms.

The results obtained in the first series were as follows:

\begin{tabular}{|c|c|c|c|c|}
\hline & SOLUBI & of MIXT & ES OF Sor & DIUM AND Potassium Su \\
\hline $\operatorname{lo}_{0}$ & $\begin{array}{l}\text { Per cent. } \\
\mathrm{K}_{2} \mathrm{SO}_{4} \\
\text { in solution. }\end{array}$ & $\begin{array}{l}\text { Per cent. } \\
\text { Na:so. } \\
\text { in solution. }\end{array}$ & $\begin{array}{l}\text { Per cent. } \\
\mathrm{K}_{2} \mathrm{SO}_{4} \\
\text { in residue. }\end{array}$ & Remarks. \\
\hline & Io. 93 & $5 \cdot 7^{2}$ & $88.97\}$ & Mixtures \\
\hline$\ldots \ldots$ & Io. 82 & $5 \cdot 78$ & $84.84\}$ & Mingtures. \\
\hline$\ldots \ldots$ & 9.71 & 8.22 & 78.16 & $\begin{array}{l}\text { Original } \mathrm{K}_{2} \mathrm{SO}_{4} \text { not all dissolved in hot } \\
\text { solution. }\end{array}$ \\
\hline$\ldots \ldots$ & $7 \cdot 98$ & 13.94 & $77 \cdot 3 \mathrm{I}$ & $\begin{array}{l}\text { Original } \mathrm{K}_{2} \mathrm{SO}_{4} \text { not all dissolved in hot } \\
\text { solution. }\end{array}$ \\
\hline $5 \ldots \ldots$ & $7 \cdot 53$ & 15.92 & $77 \cdot 40$ & $\begin{array}{l}\text { Original } \mathrm{K}_{2} \mathrm{SO}_{4} \text { not all dissolved in hot } \\
\text { solution. }\end{array}$ \\
\hline$\ldots$ & $7 \cdot 47$ & 16.80 & 74.67 & $\begin{array}{l}\text { Original } \mathrm{Na}_{2} \mathrm{SO}_{4} \text { not all dissolved in hot } \\
\text { solution. }\end{array}$ \\
\hline 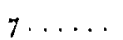 & 6.89 & $19 \cdot 5^{6}$ & $75 \cdot 32$ & Both salts dissolved in hot solution. \\
\hline$\cdots$ & 6.59 & 2 I. 28 & $74.9 \mathrm{I}$ & Both salts dissolved in hot solution. \\
\hline$\ldots$ & 6.08 & $23 \cdot 74$ & $74 \cdot 37$ & $\begin{array}{l}\text { Solution slightly supersaturated with re- } \\
\text { spect to } \mathrm{Na}_{2} \mathrm{SO}_{4} \cdot \mathrm{IOH}_{2} \mathrm{O} \text {. }\end{array}$ \\
\hline & 6.33 & $22 \cdot 56$ & $24.86\}$ & \\
\hline & 6.24 & 22.68 & $8.12\}$ & wres containing \\
\hline
\end{tabular}

The results given above are unsatisfactory in some respects, but they show certain things and are given for what they are worth. First, they show clearly the limits outside of which mixtures are formed for in Nos. 1 and 2 and ro and II, the solubility results are constant, while the residues vary. Nos. 3-9 show variable solubility, indicating but one phase present in each case instead of two but the residues are not constant in composition as a double salt would be, nor do they vary regularly with the composition of the solution, as mixed crystals should do. There is, however, a difference of nearly four per cent. in the composition of the residues, which is much greater than could be accounted for by impurities adhering from the solution, and indicates that the residues are variable in composition, due to the formation of mixed crystals. The irregular variation is pretty certainly due to equilibrium not being completely reached in the crystals. In No. 6 , the presence of solid sodium sulfate in the residue at first would tend to form mixed crystals with the maximum amount of that salt present and when once formed, the slight change of composition necessary for equilibrium with the solution would require a long time. The same may be said of Nos. 3-5 with regard to potassium sulfate.

In the second series of experiments, calculated mixtures of the single salts and water were used in such proportions that all salts should be dis- 
solved when hot and crystallize a small amount of the single phase on cooling. The mixtures were shaken as before at $25^{\circ}$. The results are given in Table II.

TABLE II.

\begin{tabular}{|c|c|c|c|}
\hline No. & $\begin{array}{c}\text { Per cent. } \mathrm{K}_{2} \mathrm{SO}_{4} . \\
\text { in solution. }\end{array}$ & $\begin{array}{l}\text { Percent. } \mathrm{Na}_{2} \mathrm{SO}_{4} \\
\text { in solution. }\end{array}$ & $\begin{array}{l}\text { Per cent. } \mathrm{K}_{2} \mathrm{SO}_{4} \\
\text { in residue. }\end{array}$ \\
\hline$A \ldots$ & 9.06 & Io. 14 & 77.24 \\
\hline$B \ldots \ldots \ldots \ldots \ldots \ldots \ldots$ & 8.04 & 14.16 & 76.64 \\
\hline $\mathcal{C} \ldots \ldots \ldots \ldots \ldots \ldots$ & 6.91 & 19.40 & 75.22 \\
\hline$D, \ldots \ldots \ldots \ldots \ldots \ldots$, & 6.52 & 21.17 & 75.86 \\
\hline
\end{tabular}

Comparing the solubilities in Table II with those in Table I, it will be seen that all four are within the limits which yield a single solid. The residues were granular and on this account could be freed very easily indeed from the mother liquor. Their difference in composition cannot be due to impurities from solution but to the formation of mixed crystals. The fact that the residue of $D$ contains somewhat more potassium sulfate than that of $C$, is undoubtedly due to the fact that perfect equilibrium is established very slowly in the solid.

For the third series, two mixtures were prepared using such proportions of salts and water that a single solid in small amount should be formed from solutions which were very near opposit limits. The amounts used were:

\begin{tabular}{|c|c|c|c|}
\hline & $\begin{array}{l}\mathrm{K}_{2} \mathrm{SO}_{4} . \\
\text { Grams. }\end{array}$ & $\begin{array}{l}\mathrm{Na}_{2} \mathrm{SO}_{4} \\
\text { Grams. }\end{array}$ & $\begin{array}{r}\mathrm{H}_{2} \mathrm{O} . \\
\text { cc. }\end{array}$ \\
\hline$I \ldots \ldots \ldots \ldots \ldots \ldots$ & 17 . & 14. & 125 \\
\hline III $\ldots \ldots \ldots \ldots \ldots, \ldots$ & I4. & 40. & 125 \\
\hline
\end{tabular}

The salts and water were warmed till all dissolved and then allowed to cool in the thermostat without shaking. After several days, the small crops of crystals were removed and analyzed. The solutions were not analyzed, but from the original proportions used, would have approximately the composition given in Table III. The residues were analyzed in duplicate.

\begin{tabular}{|c|c|c|c|c|}
\hline \multirow{2}{*}{ No. } & \multicolumn{2}{|c|}{ TABLE III. } & \multirow{2}{*}{\multicolumn{2}{|c|}{$\begin{array}{l}\text { Per cent. } \mathrm{K}_{2} \mathrm{SO}_{4} \\
\text { in residue. }\end{array}$}} \\
\hline & $\begin{array}{c}\text { Per cent. } \mathrm{K}_{2} \mathrm{SO}_{4} \\
\text { in solution }\end{array}$ & $\begin{array}{l}\text { Per cent. } \mathrm{Na}_{2} \mathrm{SO}_{4} \\
\text { in solution }\end{array}$ & & \\
\hline I. & $\ldots 9.7$ & 8.2 & 78.08 & 77.80 \\
\hline II. & .6 .5 & $2 \mathrm{I} .2$ & $74 \cdot 38$ & $74 \cdot 33$ \\
\hline
\end{tabular}

The difference in composition of the residues is about 3.5 per cent. which shows again that the residue is variable in composition or in other words, that a limited series of mixed crystals is present and not a double salt. This conclusion confirms the work of van't Hoff and Barschall.

The limiting composition of this series of mixed crystals at $25^{\circ}$ can be approximately calculated. Taking the results in Table III as being nearly correct and assuming that the residue changes as a linear function 
of the percentage of sodium sulfate in solution, the limiting values at $25^{\circ}$ would be about 78.6 per cent. and 73.9 per cent. of potassium sulfate. These values for $25^{\circ}$ probably are very near the truth but the limits doubtless change with the temperature as van't Hoff and Barschall have indicated.

\section{Sodium and Caesium Sulfates.}

In connection with the foregoing work on potassium and sodium sulfates, we have determined the solubility of mixtures of sodium and caesium sulfates, as this case has an indirect bearing on the previous one. Caesium in its compounds does not resemble sodium even as closely as potassium does while it has a greater tendency than potassium to form double salts. If the preceding sodium potassium sulfate had been a double salt, therefore, it would be expected that caesium would form one or more also, while if mixed crystals formed in the previous case, caesium would less likely be isomorphous with sodium and the two sulfates should crystallize side by side without forming mixed crystals.

Pure caesium sulfate was prepared by evaporating a solution of the chloride with a slight excess of sulfuric acid. The residue was heated in platinum to be sure chlorides were removed, then dissolved in water and barium hydroxide added in the presence of phenolphthalein till the solution was neutral. Barium sulfate was removed by filtering and the solution evaporated to dryness. The salt is exceedingly soluble. This method of preparing the normal sulfate in considerable quantity is much easier than the method of igniting the acid sulfate with ammonium carbonate or in a current of ammonia.

Mixtures of the two sulfates and water were prepared as before and shaken at $25^{\circ}$. The determination of caesium was carried out exactly like the potassium determination previously described, a solution of ammonium chloride being used which was saturated with caesium chloroplatinate.

The following results were obtained:

\begin{tabular}{|c|c|c|c|c|}
\hline No. & $\begin{array}{c}\text { Per cent. } \\
\mathrm{Cs}_{2} \mathrm{SO}_{4} \\
\text { in solution. }\end{array}$ & $\begin{array}{c}\text { Per cent. } \\
\mathrm{Na}_{2} \mathrm{SO}_{4} \\
\text { in solution. }\end{array}$ & $\begin{array}{c}\text { Per cent. } \\
\mathrm{CS}_{2} \mathrm{SO}_{4} \\
\text { in residue. }\end{array}$ & $\begin{array}{l}\text { Empirical composi- } \\
\text { tion of tesidue. }\end{array}$ \\
\hline I & 54.65 & I I . 44 & 89.98 & ${ }_{1} \mathrm{Na}_{2} \mathrm{SO}_{4} \cdot 3 \cdot 53 \mathrm{Cs}_{2} \mathrm{SO}_{4}$ \\
\hline & $54 \cdot 5^{8}$ & I I . 63 & 78.22 & $\mathrm{INa}_{2} \mathrm{SO}_{4} \cdot \mathrm{I} \cdot 4 \mathrm{ICS}_{2} \mathrm{SO}_{4}$ \\
\hline $3 \ldots \ldots \ldots$ & $54.8 \mathrm{I}$ & I I . 25 & 34.67 & $4.8 \mathrm{Na}_{2} \mathrm{SO}_{4} \cdot \mathrm{Cs}_{2} \mathrm{SO}_{4}$ \\
\hline
\end{tabular}

The composition of the solution remains constant while the composition of the residue varies between wide limits. This shows that neither double salts form nor mixed crystals analogous to those of sodium and potassium sulfates.

It may be added that all the caesium-sodium residues contained no water showing that sodium sulfate crystallizes anhydrous at this temperature in the presence of so much dissolved salt. The decahydrate formed, however, in mixtures No. Io and i of Table I, where mixed crystals of 
sodium and potassium sulfate were mixed mechanically with sodium sulfate.

SheFfield Chemical LABoratory, Yale UNIVERSity, NEW HaVEN, CONN.

[Contribution from Kent Chemical laboratory, University of Chicago.] EQUILIBRIUM BETWEEN ALKALI-EARTH CARBONATES, CARBON DIOXIDE AND WATER.

By Herbert N. McCoy AND Herbert J. SMith.

Received January 25, 1911.

In view of the importance of an accurate knowledge of the state of equilibrium between calcium carbonate, carbon dioxide and water and the fact that previous experimenters ${ }^{1}$ had not used modern physicochemical methods, nor carried the measurements to higher pressures than 6 atmospheres, we undertook a study of the system in question.

As is well known, the concentration of dissolved lime increases with increasing concentration of carbonic acid. The theory of the equilibrium has been treated by van't Hoff, ${ }^{2}$ Bodländer ${ }^{3}$ and Stieglitz. ${ }^{4}$

The following fundamental equations govern the equilibrium:

$$
\begin{aligned}
\mathrm{H} \times \mathrm{HCO}_{3} & =k_{1} \times \mathrm{H}_{2} \mathrm{CO}_{3} . \\
\mathrm{H} \times \mathrm{CO}_{3} & =k_{2} \times \mathrm{HCO}_{3} . \\
\mathrm{Ca} \times \mathrm{CO}_{3} & =k_{3}, \text { the solubility product. } \\
\mathrm{HCO}_{3} & =2 \mathrm{Ca} . \\
\mathrm{Ca} & =\alpha \times \mathrm{Ca}\left(\mathrm{CHO}_{3}\right)_{2} .
\end{aligned}
$$

If $k$ is the equilibrium constant for reaction,

$$
\frac{\alpha \times C a\left(\mathrm{HCO}_{3}\right)_{2}}{\sqrt[3]{\mathrm{H}_{2} \mathrm{CO}_{3}}}=\sqrt[3]{\frac{k_{1} k_{3}}{4 k_{2}}}=k .
$$

Bodländer showed that Schloessing's experiments gave a good equilibrium constant and calculated $k_{3}$, the solubility product of calcium carbonate, from the results. The value found is erroneous ${ }^{5}$ owing to the use of an incorrect value for the secondary ionization constant of carbonic acid. Stieglitz has made a critical recalculation of the solubility product from Schloessing's experiments and other available data giving $k_{1}$ and $k_{2}$. Seyler and Lloyd ${ }^{6}$ have also studied the problem under conditions applicable to geological problems.

In our experiments, for partial pressures of carbon dioxide, less than

${ }^{1}$ Schloesing, Compt. rend., 74, 1552; 75, 70 (1872); Engler, Ann. chim. phys., [6] I3, 348 (I888). Seyler and Lloyd, J. Chem. Soc., 95, 1347 (Igog).

$2 Z$. physik. Chem., I, 505 (1887).

3 Ibid, 35, 23 (1900).

4 Carnegie Inst. Publication, 107, 233 (1908).

"Stieglitz, Loc. cit. McCoy, Am. Chem. J., 29, 437 (I903.)

- Loc. cit. 